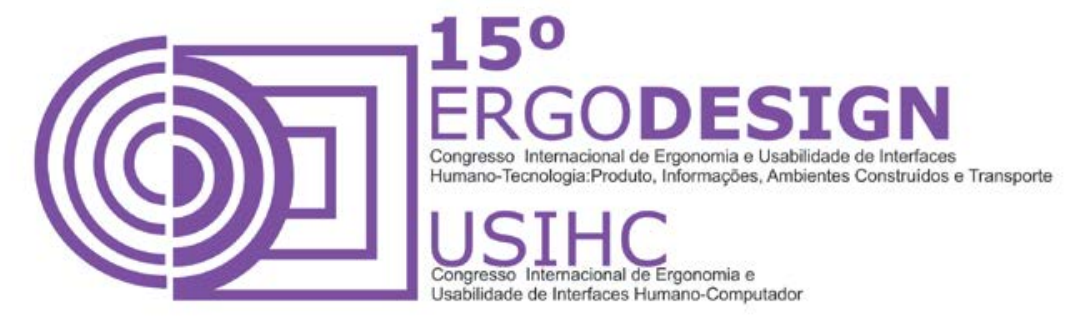

\title{
AVALIAÇÃO DO DESEMPENHO TÉRMICO E CONFORTO TÉRMICO DOS USUÁRIOS EM EMPREENDIMENTOS RESIDENCIAIS HORIZONTAIS DO PROGRAMA MINHA CASA MINHA VIDA EM MACEIÓ-AL.
}

\author{
EVALUATION OF THERMAL PERFORMANCE AND THERMAL \\ COMFORT OF USERS IN HORIZONTAL RESIDENTIAL ENTERPRISE \\ OF PROGRAMA MINHA CASA MINHA VIDA IN MACEIÓ-AL.
}

\author{
DANTAS, Cristine (1); \\ BARBIRATO, Gianna (2);
}

(1) FAU/UFAL, Mestranda do Programa de Pós-Graduação em Arquitetura e Urbanismo Universidade Federal de Alagoas- UFAL - e-mail: crisdantas 32@hotmail.com

(2) FAU/UFAL, Professora Doutora do Programa de Pós-Graduação em Arquitetura e Urbanismo - Universidade Federal de Alagoas- UFAL - e-mail: gmb@ctec.ufal.br

\begin{abstract}
RESUMO
O presente trabalho avaliou o desempenho térmico de quartos em uma unidade residencial de um empreendimento habitacional horizontal localizado na cidade de Maceió - AL, pertencente ao PMCMV, através de simulações computacionais com o programa EnergyPlus v.8.1 e o conforto térmico interno, estabelecido a partir de estudos da literatura técnica existente. Os resultados indicaram que tanto o quarto filhos, quanto o quarto casal obtiveram os melhores resultados de desempenho térmico e conforto térmico na simulação 01 e os piores na simulação 02 . O que reforça a importância de adequação das construções às condições climáticas na qual estão inseridas.
\end{abstract}

Palavras-chave: desempenho térmico de edificações, conforto térmico dos usuários, empreendimentos residenciais horizontais.

\section{ABSTRACT}

The present study evaluated the thermal performance of rooms in a residential unit of a horizontal housing development located in the city of Maceió-AL, belonging to the PMCMV, through computer simulations with the EnergyPlus program v. 8.1 and the indoor thermal comfort, established on the basis of the existing technical literature studies. The results indicated that both the kids room, as the fourth couple obtained the best results of thermal performance and thermal comfort in the simulation in the simulation and the worst 01 02. Which reinforces the importance of adequacy of buildings the climatic conditions in which they are inserted.

Keywords: thermal performance of buildings; thermal comfort of users; horizontal residential enterprise. 


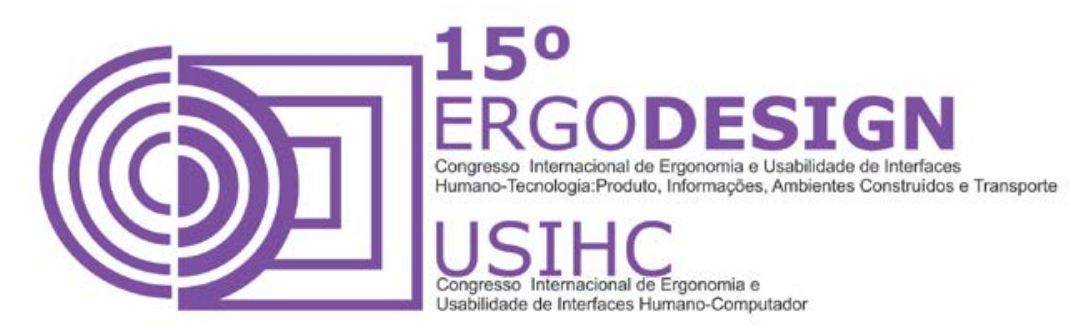

\section{INTRODUÇÃO}

Em março de 2009, o governo federal lançou o ambicioso Programa Minha Casa Minha Vida (PMCMV) anunciado com o objetivo de promover a construção de um milhão de residências; no qual contempla por um lado o atendimento às camadas de renda abaixo de três salários mínimos, com volume inédito de subsídios públicos para essa faixa, e por outro lado a construção, pelo mercado, de moradias para as faixas de renda acima de três salários mínimos, com mecanismos de facilitação da viabilidade financeira, que envolvem também alguns subsídios públicos.

Não há dúvida da importância de ambas as dimensões do programa, embora seja relevante registrar que aquela destinada às faixas de renda mais baixas é, sem dúvida, a mais urgente; dado que nelas se concentra parte significativa do déficit habitacional brasileiro, cerca de 5,6 milhões de domicílios. No entanto, ao assumir como meta principal uma perspectiva quantitativa, a produção de um milhão de casas, o Programa Minha Casa Minha Vida deixa em segundo plano os aspectos de qualidade arquitetônica e os impactos urbanos de sua produção. De forma geral, a equação entre quantidade e qualidade, que incide sobre a constante redução dos custos da construção, muitas vezes, é possibilitada pela ausência da atuação pública efetiva sobre as leis municipais de uso e ocupação do solo, dos códigos de obra e de alguns parâmetros técnicos mínimos para a implantação dos empreendimentos enquadrados pelo PMCMV, sendo pouco rigorosos com relação aos interesses dos empreendedores imobiliários, tornando-se um dos desafios mais difíceis para a qualidade arquitetônica e urbanística.

A produção em escala de empreendimentos residenciais horizontais, que se enquadram neste programa, vem sendo utilizada na diluição dos preços do terreno e na construção de um maior número de unidades habitacionais; o que reforça a tendência de espraiamento territorial na medida em que parte das grandes glebas disponíveis se encontra fora dos centros urbanos mais consolidados. Já na escala de implantação, algumas incorporadoras e construtoras que atendem ao PMCMV adotam modalidades padronizadas de tipologias arquitetônicas e construtivas nos empreendimentos residenciais horizontais que se repetem por todo o País - os "carimbos" - desconsiderando as condições socioespaciais, ambientais e topográficas dos terrenos nos quais se inserem, na tentativa de minimizar custos e racionalizar a construção. $O$ que reflete negativamente através de fortes limitações, na escolha das melhores orientações das edificações, para boa captação de iluminação e ventilação naturais, adequações projetuais de acordo com as necessidades e exigências específicas de cada região ou zona bioclimática, que prejudicam principalmente o desempenho térmico desses empreendimentos e o conforto térmico dos seus usuários.

Os empreendimentos habitacionais horizontais devem oferecer condições de habitabilidade, propiciando aos seus ocupantes condições ambientais interiores capazes de protegê-los das variações climáticas e criando um local digno e adequado a suprir as necessidades básicas. Diversos estudos sobre qualidade das habitações inseridas em programas de interesse social vêm sendo realizados, especialmente no meio acadêmico. Sendo necessário, portanto, uma constante troca de informações entre os setores públicos ligados à construção, projetistas e engenheiros de obra e pesquisadores que subsidiem esses programas 


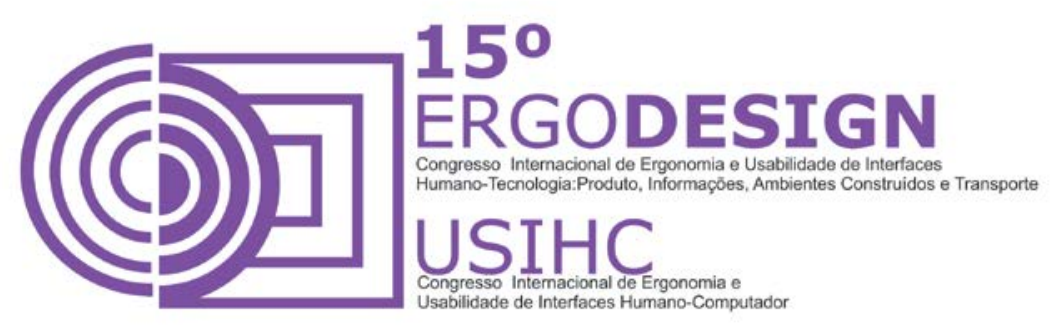

quanto aos aspectos climáticos particulares de cada região que devem ser observados; uma vez que o desempenho térmico é uma base importante para que condições de habitabilidade sejam alcançadas em uma edificação.

Logo, o principal propósito de avaliar o desempenho térmico e conforto térmicos dos usuários em empreendimentos residenciais horizontais do Programa Minha Casa Minha Vida, localizados em Maceió - AL; deve-se a uma tentativa de contribuição com referências úteis ao desenvolvimento de habitações populares que apresentem qualidade no seu desempenho térmico e conforto térmico dos seus usuários. Considera-se, que ao agregar melhorias no projeto arquitetônico em sua fase de concepção, como estudos prévios de materiais, componentes, análise de condições de exposição ao vento e orientação solar, pode-se obter satisfatórias condições de conforto térmico dos usuários.

\section{OBJETIVO}

Avaliar o desempenho térmico das edificações e o conforto térmico interno em exemplares de empreendimentos habitacionais horizontais do Programa Minha Casa Minha Vida - PMCMV, tendo como estudo de caso um empreendimento habitacional horizontal localizado no contexto climático da cidade de Maceió - AL; de modo a contribuir para a discussão sobre elaboração de projetos termicamente confortáveis, destacando a importância da utilização dos recursos da climatização natural nesses tipos de edificações.

\section{METODOLOGIA}

A metodologia utilizada neste artigo foi uma avaliação do desempenho térmico dos quartos casal e filhos de um Modelo Base de projeto arquitetônico habitacional horizontal, que atende aos requisitos mínimos do Programa Minha Casa Minha Vida, no contexto climático da cidade de Maceió - AL e conforto térmico dos seus usuários; através da simulação computacional pelo programa EnergyPlus versão 8.1 (DOE, 2013) e aplicando-se, aos resultados obtidos, intervalos de conforto provenientes da literatura técnica existente na área, considerados aceitáveis para usuários expostos ao clima quente e úmido.

\subsection{Caracterização do Objeto de Estudo}

Foi escolhido como objeto de estudo o Residencial Novo Jardim, localizado na Rua Dr. Juracy Teixeira, S/N, Conjunto Estáquio Gomes, no bairro Tabuleiro dos Martins, em MaceióAL. O Residencial Novo Jardim é constituído por 05 módulos, o módulo I contém um total de 527 lotes, o módulo II contém um total de 526 lotes, o módulo III contém um total de 526 lotes, 0 módulo IV contém um total de 526 lotes e o módulo V contém um total de 379 lotes, sendo 02 comerciais (ver Figura 01). 


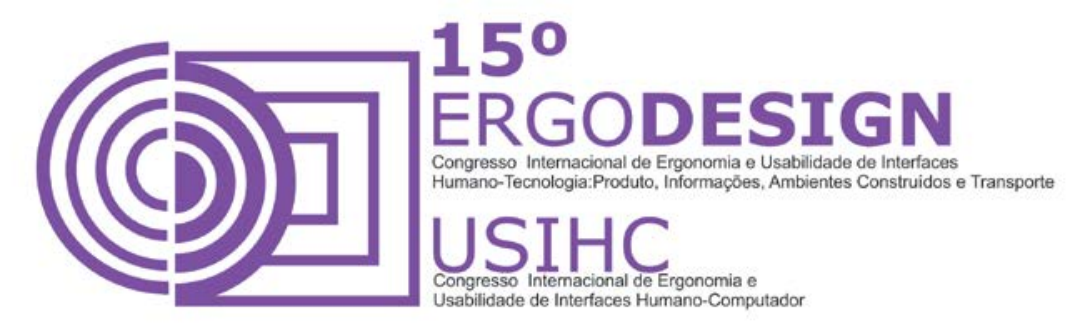

A partir dessas informações, foi selecionada uma unidade residencial que serviu como Modelo Base (localizada no Lote 02, Quadra A do Módulo I). Essa unidade residencial possui área construída de $51,00 \mathrm{~m}^{2}$; dividida em um quarto casal, um quarto filhos, circulação, uma sala estar/jantar, uma cozinha, um banheiro e terraço. O pé direito da edificação é de 2,6m (ver Figura 02).

Figura 01: Planta de Situação do Residencial Novo Jardim Sem Escala.

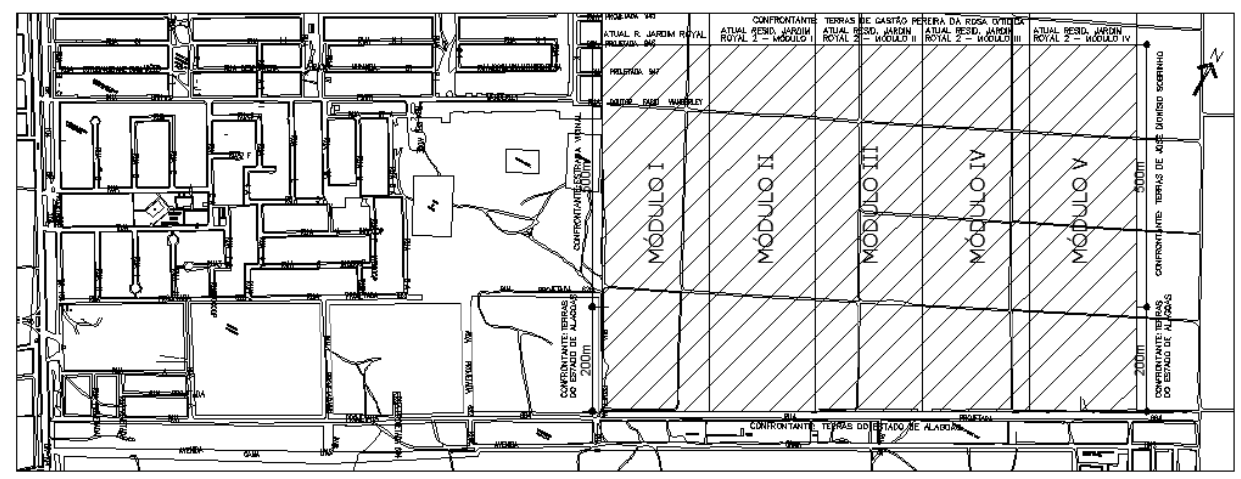

Fonte: Construtora ENGENHARQ.

Figura 02: Planta Baixa do Modelo Base Sem Escala.

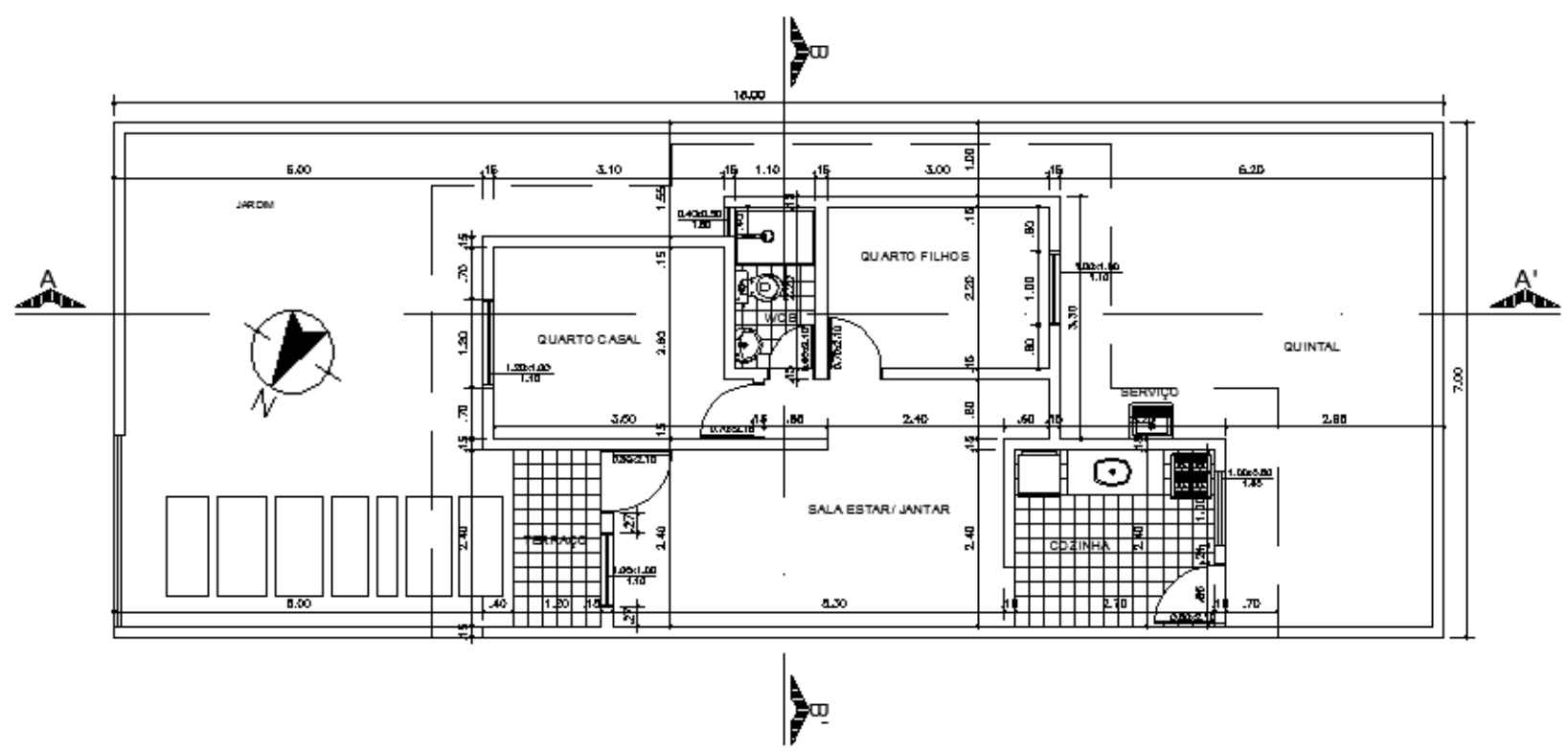

Fonte: Construtora ENGENHARQ. 

interno.

O Quadro 01 a seguir descreve o envelope do Modelo Base e as áreas de cada ambiente

Quadro 01: Síntese do envelope do Modelo Base.

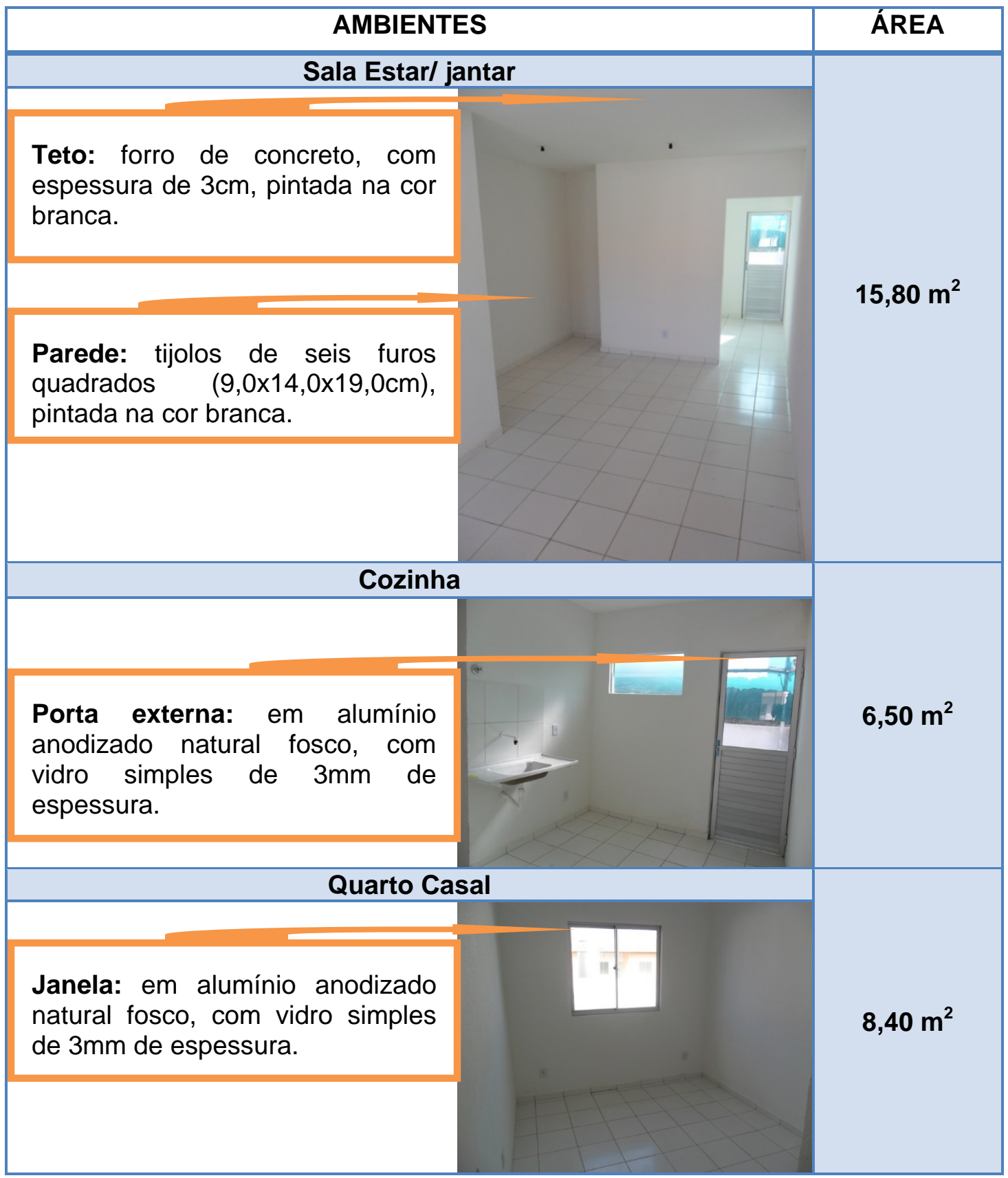



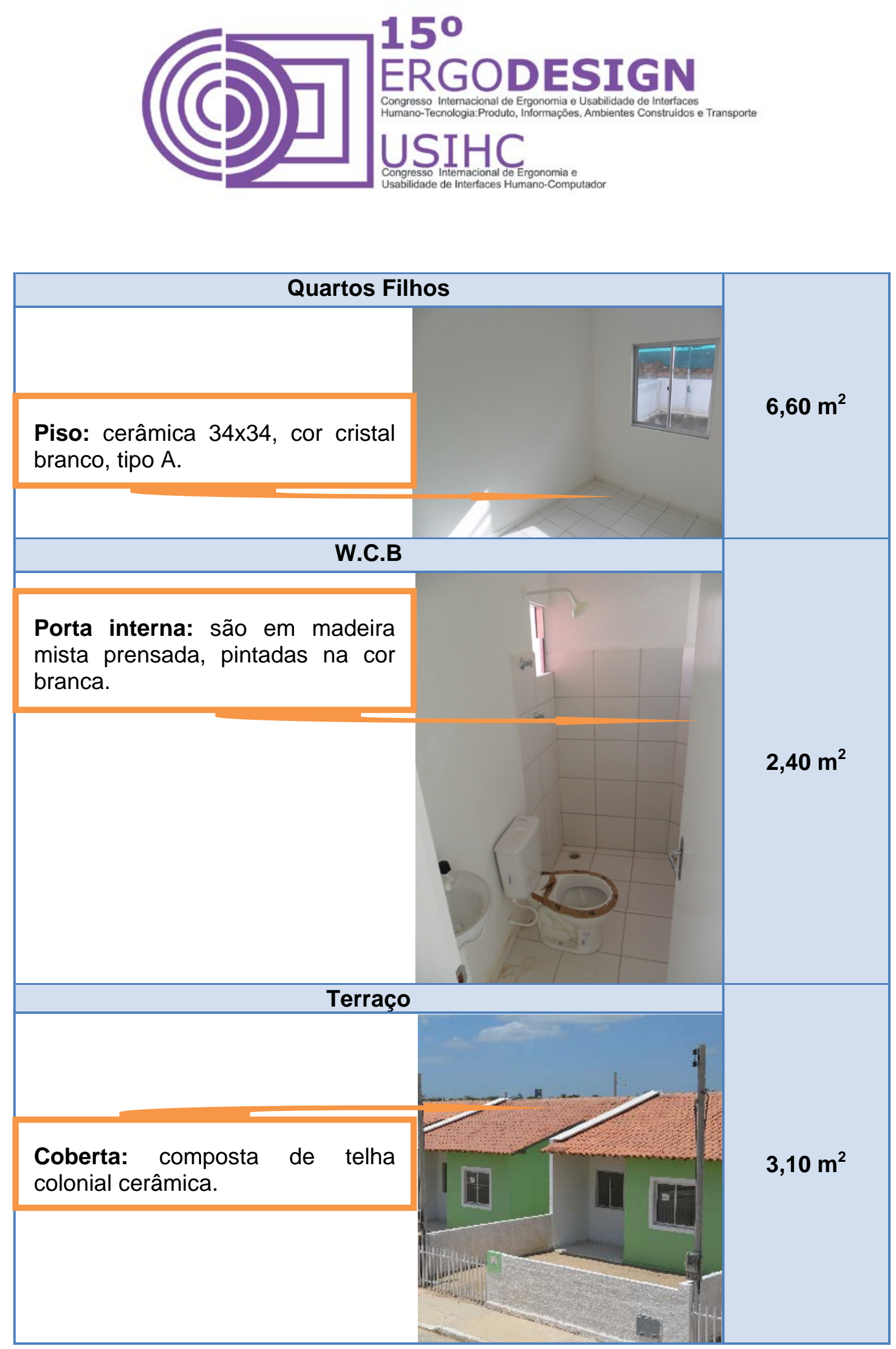

Fonte: Acervo pessoal. 


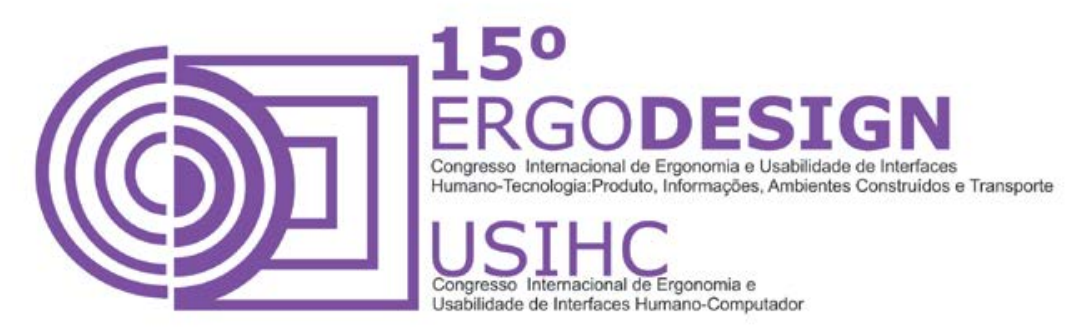

\subsection{Simulação Computacional}

O Modelo Base foi dividido em "zonas térmicas" para serem analisadas, depois foram inseridos no programa computacional EnergyPlus os dados climáticos da cidade de Maceió extraídos através de arquivos no formato EPW e as características construtivas dos materiais utilizados na edificação. A simulação da ventilação natural foi feita através do algoritmo COMIS (Conjunction of Multizone Infiltration Specialists) integrado ao programa EnergyPlus e as temperaturas do solo utilizadas nas simulações foram calculadas através do programa Slab, vinculado ao EnergyPlus.

Tendo em vista a influência que determinados parâmetros ${ }^{1}$ possuem sobre o desempenho térmico e o conforto dos usuários de empreendimentos habitacionais horizontais, foram definidos parâmetros de simulação fixos e variáveis para o Modelo Base.

- Parâmetros fixos:

1) Tipos de aberturas: correspondem ao do Modelo Base;

2) Padrão de ocupação: são iguais para todos os dias da semana e representam uma família composta por quatro moradores: um casal e dois filhos;

3) Rotinas de iluminação: foram definidas conforme o padrão de ocupação dos ambientes.

- Parâmetros variáveis:

1) Tipos de parede: parede com tijolos de seis furos quadrados, com espessura total de $14 \mathrm{~cm}$ pintada na cor branca (referente ao Modelo Base) e parede de concreto maciço, com espessura total de $10 \mathrm{~cm}$ pintada na cor marrom escuro (selecionada conforme os valores de absortância e transmitância acima do que é recomendado na parte 3 da norma NBR 15220, 2005);

2) Tipos de cobertura: cobertura composta por forro de concreto, com espessura de $3 \mathrm{~cm}$ pintada na cor branca e telha colonial cerâmica (referente ao Modelo Base) e cobertura de telha de barro sem forro (selecionada conforme os valores de absortância e transmitância acima do que é recomendado na parte 3 da norma NBR 15220, 2005);

3) Tipos de ventilação: foram divididas em ventilação parcial (7h às 22h) e ventilação total (janelas e portas abertas às $24 \mathrm{~h}$ do dia).

\footnotetext{
${ }^{1}$ A definição dos parâmetros de simulações foi baseado nas recomendações descritas nas normas NBR 15220-3 (ABNT, 2005) e NBR 15575-4 (ABNT, 2005) para a zona bioclimática 8, na qual se enquadra a cidade de Maceió - AL. No entanto, outras alternativas que não estão descritas nas normas foram consideradas com o intuito de obter-se resultados mais específicos.
} 


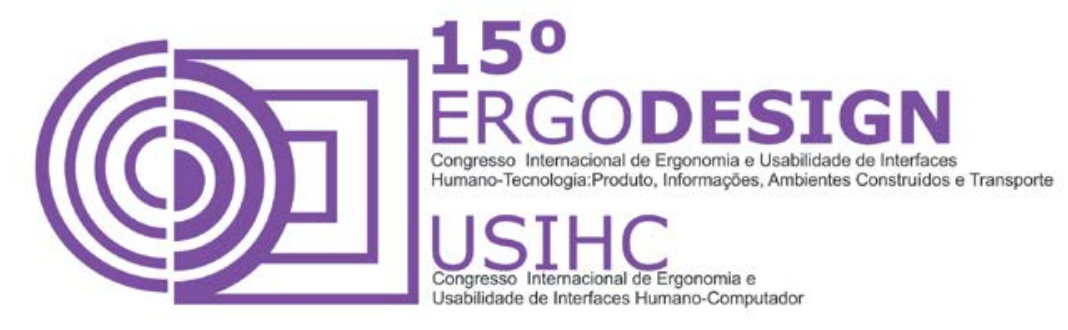

\section{RESULTADOS E DISCUSSÕES}

Com o intuito de comparar o desempenho térmico dos quartos casal e filhos do Modelo Base foram feitas composições com os parâmetros variáveis, anteriormente citados. O quadro 02 a seguir apresenta as composições utilizadas nas simulações.

Quadro 02: composição dos parâmetros variáveis dos Modelos Base para a simulação computacional.

\begin{tabular}{|c|c|}
\hline SIMULAÇÃO 01 & $\begin{array}{l}\text { Parede: composta com tijolos de seis furos quadrados, com espessura } \\
\text { total de } 14 \mathrm{~cm} \text { e pintura na cor branca; Cobertura: composta por forro de } \\
\text { concreto, com espessura de } 3 \mathrm{~cm} \text {, pintada na cor branca e telha colonial } \\
\text { cerâmica; Ventilação: parcial. }\end{array}$ \\
\hline SIMULAÇÃO 02 & $\begin{array}{l}\text { Parede: Parede de concreto maciço, com espessura total de } 10 \mathrm{~cm} \text { e } \\
\text { pintura na cor marrom escuro; Cobertura: Cobertura composta de telha } \\
\text { colonial cerâmica, sem forro; Ventilação: parcial. }\end{array}$ \\
\hline SIMULAÇÃO 03 & $\begin{array}{l}\text { Parede: composta com tijolos de seis furos quadrados, com espessura } \\
\text { total de } 14 \mathrm{~cm} \text { e pintura na cor branca; Cobertura: composta por forro de } \\
\text { concreto, com espessura de } 3 \mathrm{~cm} \text {, pintada na cor branca e telha colonial } \\
\text { cerâmica; Ventilação: total. }\end{array}$ \\
\hline SIMULAÇÃO 04 & $\begin{array}{l}\text { Parede: Parede de concreto maciço, com espessura total de } 10 \mathrm{~cm} \text { e } \\
\text { pintura na cor marrom escuro; Cobertura: Cobertura composta de telha } \\
\text { colonial cerâmica, sem forro; Ventilação: total. }\end{array}$ \\
\hline
\end{tabular}

Após as simulações, foram analisados os dois ambientes de longa permanência (quarto casal e quarto filhos). Os intervalos de conforto térmico utilizados nos gráficos do quarto casal e do quarto filhos (temperatura de neutralidade $=26^{\circ} \mathrm{C}$, limite superior de conforto $=29.5^{\circ} \mathrm{C}$ e limite inferior de conforto $=24.5^{\circ} \mathrm{C}$ ) foram baseados nos índices de conforto térmico dos estudos de Pereira e Assis (2010) e Costa (2011), em concordância ao índice adaptativo 8 de DeDear e Bragger (2002) e com seu aprimoramento em Peeters et al (2009).

\subsection{Quarto Casal}

Foram observados os seguintes resultados: na Simulação 01, o Quarto Casal obteve $84 \%$ de suas horas de temperaturas internas do ar dentro do limite de conforto (0\% acima do limite superior de conforto e 16\% abaixo do limite inferior de conforto); já na Simulação 02 foram $65 \%$ de suas horas de temperaturas internas do ar que estiveram dentro do limite de conforto (28\% acima do limite superior de conforto e $7 \%$ abaixo do limite inferior de conforto). Na Simulação 03, o Quarto Casal obteve $81,15 \%$ de suas horas de temperaturas internas do ar dentro do limite de conforto $(0,02 \%$ acima do limite superior de conforto e $18,83 \%$ abaixo do 


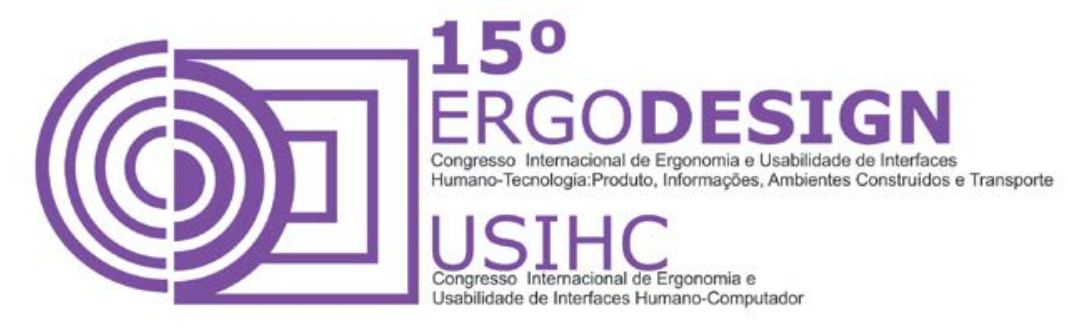

limite inferior de conforto) e na Simulação 04 foram $78 \%$ de suas horas de temperaturas internas do ar que estiveram dentro do limite de conforto (12\% acima do limite superior de conforto e 10\% abaixo do limite inferior de conforto). Como demonstra o Gráfico 01 a seguir.

Gráfico 01 - Comparação anual das temperaturas do ar nos limites de conforto do Quarto Casal, conforme os parâmetros das Simulações 01, 02, 03 e 04.

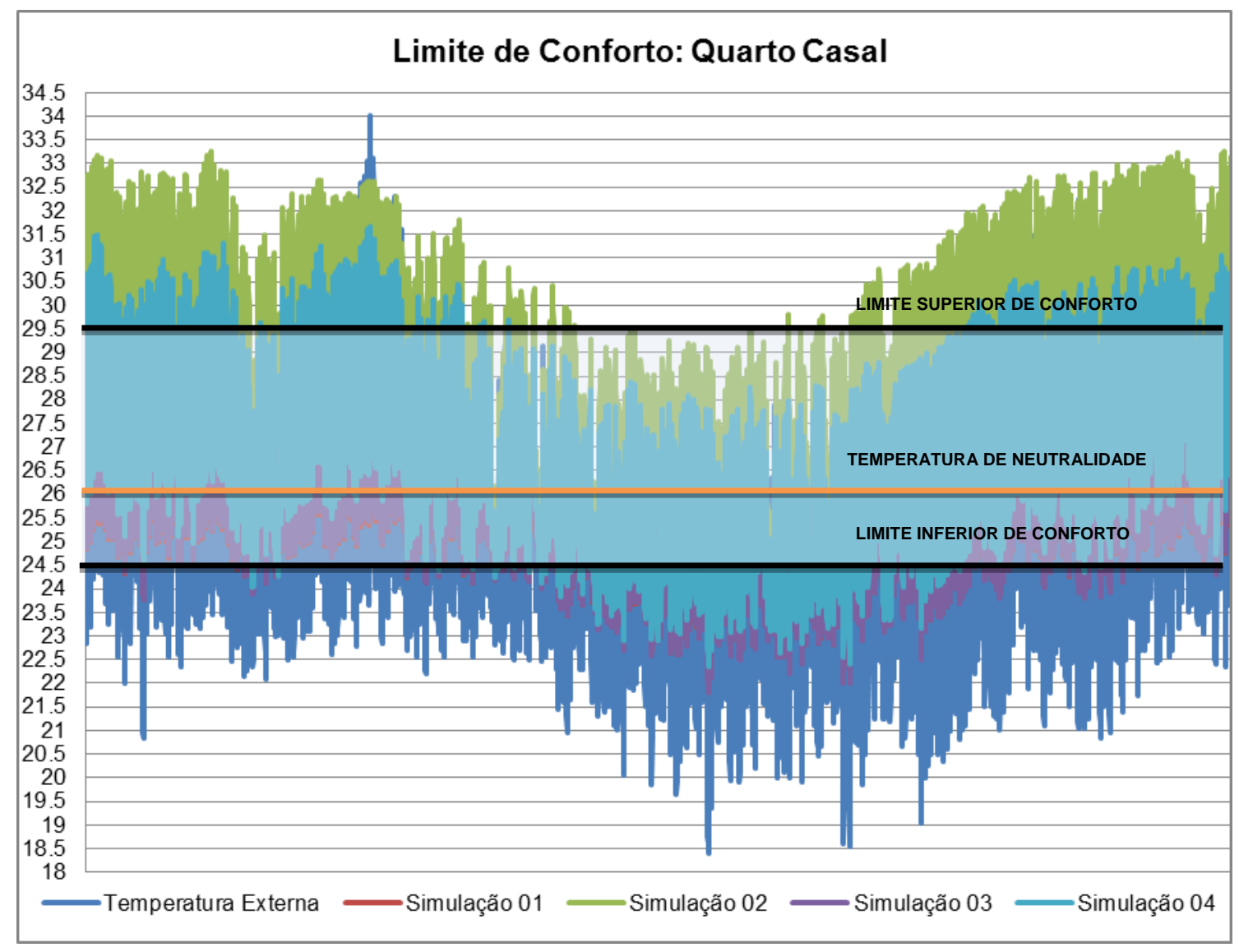

Fonte: Simulações realizadas no programa computacional EnergyPlus versão 8.1 (DOE, 2013).

Com relação ao desempenho térmico do quarto casal, os valores de temperaturas internas anuais foram os seguintes: Simulações 01 com temperatura máxima $=28,5^{\circ} \mathrm{C}$, temperatura média $=25,7^{\circ} \mathrm{C}$ e temperatura mínima $=21,8^{\circ} \mathrm{C}$; Simulações $02 \mathrm{com}$ temperatura máxima $=33,2^{\circ} \mathrm{C}$, temperatura média $=27,8^{\circ} \mathrm{C}$ e temperatura mínima $=22,4^{\circ} \mathrm{C}$; Simulações 03 com temperatura máxima $=29,6^{\circ} \mathrm{C}$, temperatura média $=25,7^{\circ} \mathrm{C}$ e temperatura mínima $=$ $21,7^{\circ} \mathrm{C}$; e Simulações $04 \mathrm{com}$ temperatura máxima $=31,6^{\circ} \mathrm{C}$, temperatura média $=26,9^{\circ} \mathrm{C}$ e temperatura mínima $=22,3^{\circ} \mathrm{C}$. 


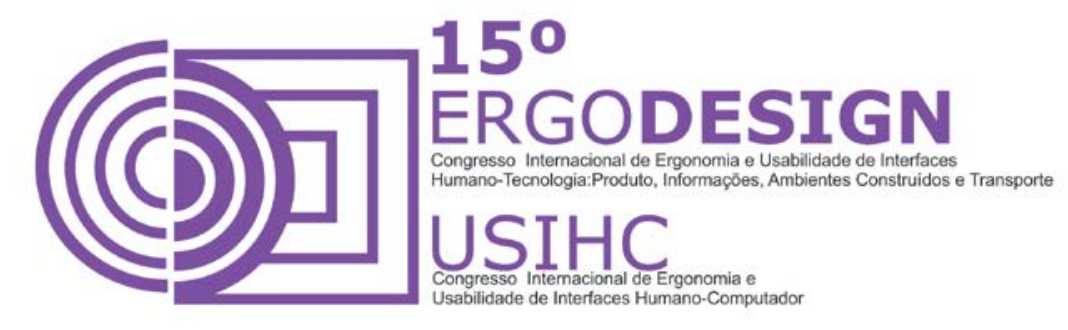

\subsection{Quarto Filhos}

Foram observados os seguintes resultados: na Simulação 01, o Quarto Filhos obteve $86 \%$ de suas horas de temperaturas internas do ar dentro do limite de conforto (0\% acima do limite superior de conforto e 14\% abaixo do limite inferior de conforto); já na Simulação 02 foram $67 \%$ de suas horas de temperaturas internas do ar que estiveram dentro do limite de conforto (27\% acima do limite superior de conforto e $6 \%$ abaixo do limite inferior de conforto). $\mathrm{Na}$ Simulação 03, o Quarto Filhos obteve $80 \%$ de suas horas de temperaturas internas do ar dentro do limite de conforto (2\% acima do limite superior de conforto e $18 \%$ abaixo do limite inferior de conforto) e na Simulação 04 foram $81 \%$ de suas horas de temperaturas internas do ar que estiveram dentro do limite de conforto (10\% acima do limite superior de conforto e $9 \%$ abaixo do limite inferior de conforto). Como demonstra o Gráfico 02 a seguir.

Gráfico 02 - Comparação anual das temperaturas do ar nos limites de conforto do Quarto Filhos, conforme os parâmetros das Simulações 01, 02, 03 e 04.

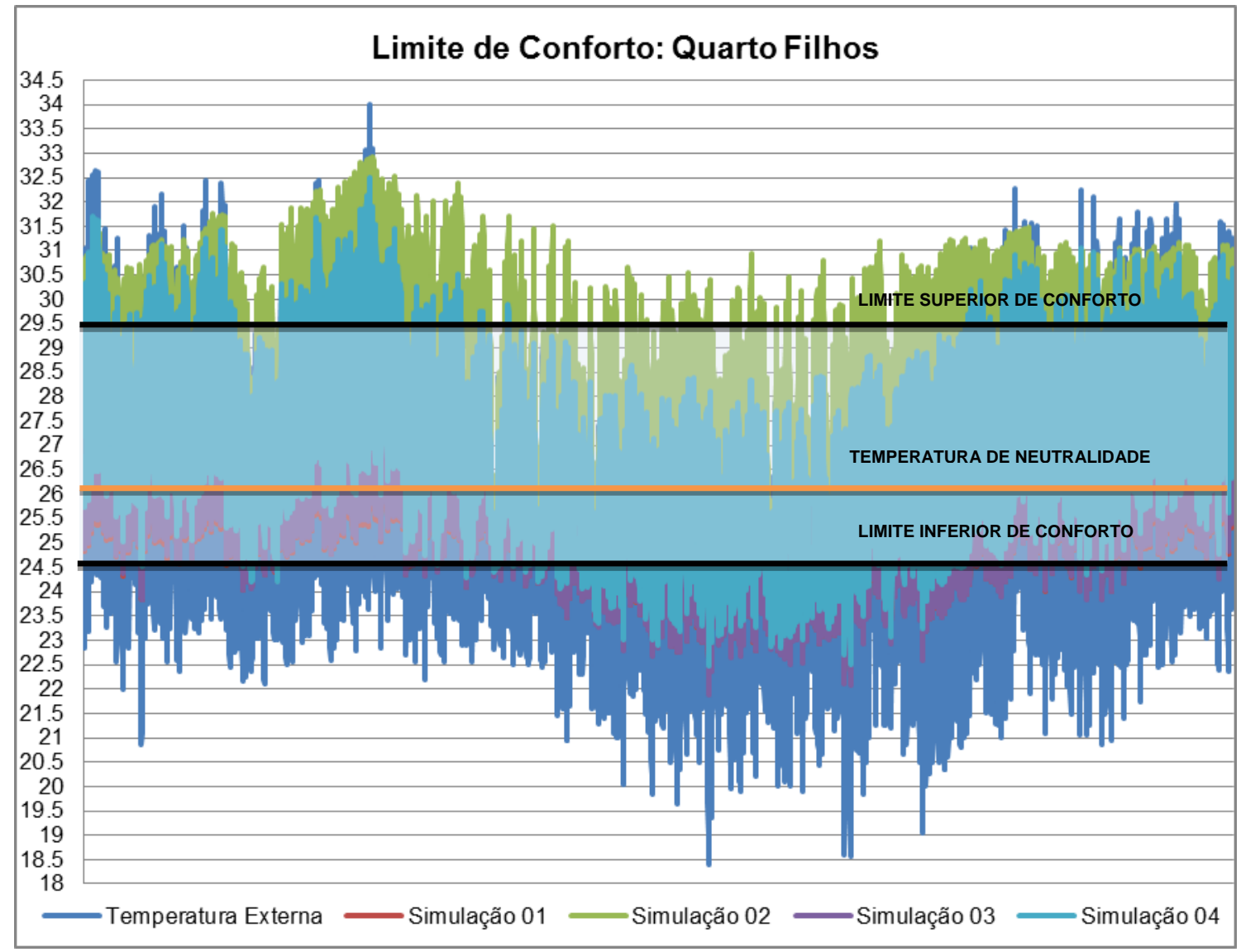

Fonte: Programa computacional EnergyPlus versão 8.1 (DOE, 2013). 


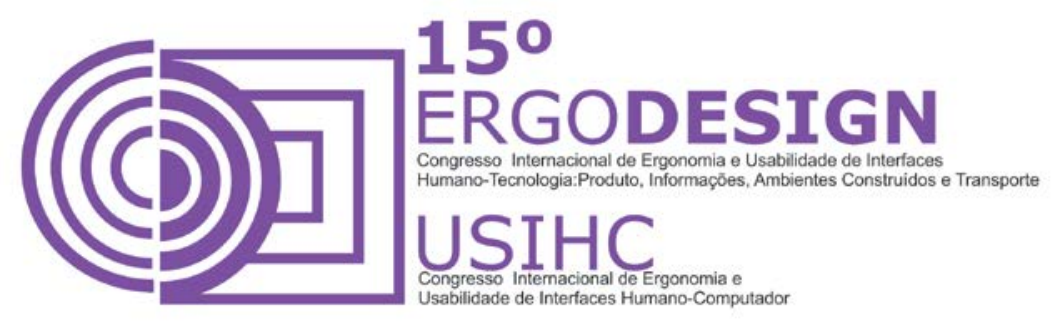

Com relação ao desempenho térmico do quarto filhos, os valores de temperaturas internas anuais foram as seguintes: Simulações $01 \mathrm{com}$ temperatura máxima $=28,4^{\circ} \mathrm{C}$, temperatura média $=25,8^{\circ} \mathrm{C}$ e temperatura mínima $=21,9^{\circ} \mathrm{C}$; Simulações $02 \mathrm{com}$ temperatura máxima $=32,9^{\circ} \mathrm{C}$, temperatura média $=27,8^{\circ} \mathrm{C}$ e temperatura mínima $=22,6^{\circ} \mathrm{C}$; Simulações 03 com temperatura máxima $=31,0^{\circ} \mathrm{C}$, temperatura média $=25,9^{\circ} \mathrm{C}$ e temperatura mínima $=$ $21,8^{\circ} \mathrm{C}$; e Simulações 04 com temperatura máxima $=32,4^{\circ} \mathrm{C}$, temperatura média $=26,9^{\circ} \mathrm{C}$ e temperatura mínima $=22,4^{\circ} \mathrm{C}$.

\section{CONSIDERAÇÕES FINAIS}

Através da análise dos resultados obtidos nas simulações do Quarto Casal e Quarto Filhos, pode-se perceber que o Quarto Filhos foi o que obteve as melhores condições de conforto térmico (visto que este alcançou o maior número de horas confortáveis dentro do limite de conforto nas simulações 01, 02 e 04; já o Quarto Casal apenas alcançou o maior número de horas confortáveis dentro do limite de conforto na simulação 03). Outro ponto que se deve salientar é a importância tanto da ventilação natural como estratégia fundamental de conforto térmico para climas quentes e úmidos, quanto o tipo de tipologia construtiva adequada para cada tipo de clima. Logo, observou-se que tanto no Quarto Casal, quanto no Quarto filhos os resultados mais satisfatórios de desempenho térmico e conforto dos usuários foram nas simulações 01, que tinham como parâmetros variáveis o uso da ventilação parcial (7h às $22 \mathrm{~h}$ ) e as tipologias de parede e cobertura que atendiam os valores de absortância e transmitância recomendados na parte 3 da norma NBR 15220, 2005 para a zona bioclimática 8, na qual a cidade de Maceió está inserida. E os piores resultados foram nas simulações 02, que tinham como parâmetros variáveis o uso da ventilação parcial ( $7 \mathrm{~h}$ às $22 \mathrm{~h}$ ) e as tipologias de parede e cobertura que atendiam os valores de absortância e transmitância acima do que são recomendados na parte 3 da norma NBR 15220, 2005 para a zona bioclimática 8.

Desta forma, observa-se que os resultados obtidos por este artigo reforçam a importância de se buscar novos referenciais construtivos que visem à adequação climática das construções, melhorando o seu desempenho térmico e o conforto térmico de seus usuários, principalmente nas unidades residenciais horizontais que atendem ao PMCMV, que muito comumente adotam modalidades padronizadas de tipologias arquitetônicas e construtivas na tentativa de minimizar custos e racionalizar a construção. 


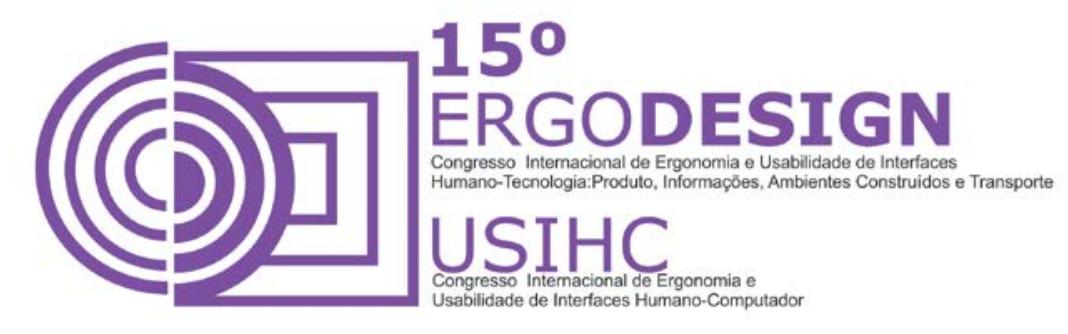

REFERÊNCIAS

ASSOCIAÇÃO BRASILEIRA DE NORMAS TÉCNICAS. NBR 15220 Desempenho térmico de edificações. Rio de Janeiro, 2005.

ASSOCIAÇÃO BRASILEIRA DE NORMAS TÉCNICAS. NBR 15575 Edifícios habitacionais de até cinco pavimentos. Rio de Janeiro: ABNT 2013.

Cartilha do MCMV. Programa Minha Casa Minha Vida. 2008. Disponível em: <http://downloads.caixa.gov.br/_arquivos/habita/mcmv/CARTILHACOMPLETA.PDF>. Acesso em: Abril de 2013.

COSTA, Ribeiro Sammea. Desempenho Térmico e Habitação: Uma Avaliação Comparativa no Contexto Climático da Zona Bioclimática 8. Dissertação de Mestrado - Programa de Pós-Graduação em Arquitetura e Urbanismo - Universidade Federal de Alagoas (UFAL), Maceió, 2011.

ENERGYPLUS. Programa de simulação computacional. Disponível em:

http://www.eere.energy.gov/buildings/energyplus

GOULART, S. V.G.; LAMBERTS, R.; FIRMINO, S. Dados climáticos para projeto e avaliação energética de edificações para 14 cidades brasileiras. $2^{\mathrm{a}}$ edição. Florianópolis. Núcleo de Pesquisa em Construção Civil. Universidade Federal de Santa Catarina. 1998.

NEGREIROS, Abreu Bianca. Análise de Métodos de Predição de Conforto Térmico de Habitação em Clima quente-úmido com Condicionamento Passivo. Dissertação de Mestrado - Programa de PósGraduação em Arquitetura e Urbanismo - Universidade Federal do Rio Grande do Norte (UFRN), Natal, 2010.

SORGATO, José Márcio. Desempenho térmico de Edificações Residenciais Unifamiliares Ventiladas Naturalmente. Dissertação de Mestrado - Programa de Pós-Graduação em Engenharia Civil (PPGEC) - Universidade Federal de Santa Catarina (UFSC), Florianópolis, 2009. 